\title{
Urban ecological infrastructure: an integrated network for ecosystem services and sustainable urban systems
}

\author{
Feng Li ${ }^{\text {a, }}$, Xusheng Liu ${ }^{b}$, Xiaoling Zhang ${ }^{c}$, Dan Zhao ${ }^{d}$, Hongxiao Liu ${ }^{a}$, Chuanbin Zhou ${ }^{\text {a }}$, \\ Rusong Wang ${ }^{\mathrm{a}}$ \\ a State Key Laboratory of Urban and Regional Ecology, Research Center for Eco-Environmental Sciences, Chinese Academy of Sciences, 18 Shuangqing Road, \\ Haidian District, Beijing 100085, China \\ ${ }^{\mathrm{b}}$ Chinese Academy of Forest Inventory and Planning, State Forestry Administration, 18 Hepingli East Street, Dongcheng District, Beijing 100714, China \\ ${ }^{c}$ Department of Public Policy, City University of Hong Kong, Hong Kong, China \\ ${ }^{\mathrm{d}}$ Beijing Municipal Institute of City Planning \& Design, 60 Nanlishi Street, Xicheng District, Beijing 100045, China
}

\section{A R T I C L E I N F O}

\section{Article history:}

Received 17 May 2015

Received in revised form

14 February 2016

Accepted 16 February 2016

Available online 24 February 2016

\section{Keywords:}

Urban ecological infrastructure

Ecosystem services

Environmental management

Urbanization

Sustainability

\begin{abstract}
A B S T R A C T
The sharp increase in global urban population and rapid expansion of impervious urban surfaces is raising concerns over more than just the quality of human life; researchers are also worried about ecosystem services and the stability and security of urban ecosystems and the infrastructures. In this paper, we define "urban ecological infrastructure" and propose an integrated framework in which the infrastructure network provides ecosystem services and sustainable urban systems despite changing landscapes and climate. We define the urban ecological infrastructure (UEI) as an organic integration of blue (water-based), green (vegetated), and grey (non-living) landscapes, combined with exits (outflows, treatment, or recycling) and arteries (corridors), at an ecosystem scale. The UEI framework represents the biotic and abiotic interactions within an ecosystem, and stresses an integrated relationship between artificial and natural systems. It links the grey, blue, and green infrastructures, and integrates them via both exits and arteries. Its insights can help to improve the circulation and reuse of resources throughout the urban ecosystem. This comprehensive conceptual framework can facilitate more rational urban development, and can improve urban ecosystem services and regional sustainability. Although understanding the form and function of UEIs is an important first step, innovative strategies are needed to address challenging obstacles such as rigid thinking, institutional fragmentation and inflexible policies. New thinking and innovative ways of acting will be required to provide a more resilient, stable, and sustainable urban system.
\end{abstract}

() 2016 Elsevier Ltd. All rights reserved.

\section{Introduction}

More than half the world's population now lives in cities, and this figure may reach 60 percent by 2030 (United Nations, 2012; Zhang, 2016). The sharp increase in the urban population and rapid expansion of impervious urban surfaces is raising concerns over more than just the quality of human life; researchers are also worried about ecosystem services and the stability and security of urban ecosystems and their infrastructures (Daily, 1997; Daily et al.,

\footnotetext{
* Corresponding author. Tel.: +861062849103.

E-mail addresses: lifeng@rcees.ac.cn (F. Li), liuxush@163.com (X. Liu), xiaoling. zhang@cityu.edu.hk (X. Zhang), zhaodan718100@163.com (D. Zhao), michellewinter@126.com (H. Liu),guyzcb@126.com (C. Zhou), wangrs@rcees.ac.cn (R. Wang).
}

2002; Li et al., 2009, 2015; Tao et al., 2015) (Table 1). Different infrastructures are built to address the increasing human demands. At current stage, ecological infrastructure is still seriously lacking. Infrastructures are the basic physical and organizational structures that society requires for its operations, and they provide the facilities required to bridge the gap between the economy and the human functions it serves (Patterson and Apostolakis, 2007; Sun et al., 2015). No city can operate without infrastructure, but infrastructures interact with ecosystems in complex ways.

Traditional infrastructure designs (also called grey infrastructure) date back to cities of antiquity, and include roads and highways, electrical grids, and systems that transport or treat potable water, sewage and storm water. However, landscape modification, habitat loss and landscape fragmentation caused by the development of grey infrastructure pose significant threats to urban 
Table 1

Challenges of constructing urban infrastructure.

\begin{tabular}{|c|c|c|c|}
\hline Category & $\begin{array}{l}\text { Basically complete } \\
\text { municipal infrastructure }\end{array}$ & $\begin{array}{l}\text { Incomplete environmental } \\
\text { infrastructure }\end{array}$ & $\begin{array}{l}\text { Absent ecological } \\
\text { infrastructure }\end{array}$ \\
\hline Demand & $\begin{array}{l}\text { water, electricity, gas, heating, greenery, } \\
\text { sanitation and wastewater treatment facilities } \\
\text { (water flush and electricity consumption) }\end{array}$ & $\begin{array}{l}\text { garbage, wastewater, exhaust gas, toilet } \\
\text { (improvement and cyclic regeneration) }\end{array}$ & $\begin{array}{l}\text { renewal of impervious surface, roof greening, rain garden, } \\
\text { wetlands, waste heat utilization, connections between corridors }\end{array}$ \\
\hline
\end{tabular}

ecosystem coherence and sustainability (Cagno et al., 2011; Kjolle et al., 2012; Serrano et al., 2002). Moreover, urban problems such as flooding, air pollution and traffic jams have revealed the weakness of the traditional grey infrastructure and its inability to cope with factors such as climate change (Kessler, 2011). Thus, great emphasis has been placed on creating infrastructure systems that are inherently more adaptable and resilient.

Urban forests, parks, woodlands, green roofs, wetlands, rivers, and other natural spaces play key roles in enhancing urban ecosystem services, improving urban environments, combating climate change, and maintaining ecological balance (Jim and Chen, 2008; Li et al., 2005). Thus, the concept of green infrastructure has been developed, referring to the combined structure, position, connectivity, and types of green spaces which together enable delivery of multiple benefits as goods and services (Mell, 2009; Schrijnen, 2000 ). At present, green infrastructure is considered to be an essential and effective way to promote ecosystem and human health in urban areas (Tzoulas et al., 2007). In addition, multiple benefits or functions, together with the planning and engineering methods, have been heavily emphasized in current studies on green infrastructure - especially practices of green roofs, permeable pavement, and sunken green space (Getter and Rowe, 2006; Scholz and Grabowiecki, 2007). Gill et al. (2007) suggest that increasing green space could reduce runoff by 4.9 percent, while increasing tree cover could reduce runoff by 5.7 percent and utilizing green roofs could reduce runoff by $11.8-14.1$ percent. Foster et al. (2011) report that permeable pavement can reduce rain runoff by $70-90$ percent, which is equivalent to the performance of lawns and woodlands. Researchers have also found that green infrastructure can have a much smaller startup cost, provide multiple functions and require less on-going maintenance (Li et al., 2014).

Although green infrastructure can make up for many of the shortages of traditional grey infrastructure, urban green infrastructure can only be identified as a 'best practice' to achieve greater urban sustainability and safety when it is combined with traditional grey infrastructure (Sijtsma et al., 2012; Wald and Hostetler, 2010). How well nearby residential and commercial areas are designed and managed greatly influences the conservation of urban biodiversity and the functionality of green infrastructure. If improperly constructed, green space can become an urban pollution source instead of a purifier. For example, storm water runoff through areas with extensive flower gardens, turf grass, and impervious surfaces can contain excessive amounts of nutrients (e.g., phosphates and nitrates), causing water eutrophication, fish deaths and the growth of invasive exotic plants (Hostetler et al., 2011). Thus, it is essential to coordinate the relationship between grey infrastructures and green infrastructures, and to create built areas that are compatible with the green infrastructure.

Because cities are complex ecosystems driven by both socioeconomic activities and natural processes, urban ecosystems need more integrated, effective, comprehensive, and multi-functional ecological infrastructures (Li et al., 2014; Wang et al., 2014). These should integrate the green and grey infrastructures with related landscape characteristics at an ecosystem scale. In this way, a collaborative symbiosis can be achieved in the form of an infrastructure that facilitates recycling and regeneration and can maintain the functionality, sustainability and vitality of the urban ecosystem. In this paper, we define "urban ecological infrastructure," and propose an integrated framework in which the infrastructure network provides ecosystem services and sustainable urban systems despite changing landscapes and climate.

\section{What is urban ecological infrastructure?}

\subsection{Definition}

The concept of Ecological Infrastructure (EI) first appeared in UNESCO's annual reports on the Man and Biosphere (MAB) Program. In the MAB report, EI was put forward as one of five principles for understanding the natural landscapes of the city, but no precise definition or description was provided. During the 1990s, the concept of urban ecological infrastructure was used in theoretical and practical research (Lockhart, 2009; Mell, 2009; Weber et al., 2008). The Conservation Fund (2009) defined EI as "strategically planned and managed networks of natural lands, working landscapes and other open spaces that conserve ecosystem values and functions and provide associated benefits to society." This emphasized the importance of natural environmental and life support systems in urban land-use planning, including green roofs, rain gardens, wetlands, and other natural or constructed facilities that promote a healthier environment.

In China, Yu's first applied the concept of EI to urban spatial planning in 2002 (Yu et al., 2001, 2005, 2008). Other scholars also put forward relevant concepts, such as the habitat network, ecological corridor, green channel, and ecological network (Ahern, 1995; Nolfi and Parisi, 1994). After approximately twenty years' development, the concept of EI and its benefits for ecosystem service and human well-being have been accepted by scientists, engineers and decision-makers. However, the definition and connotations of EI are quite vague, and the differences between EI and green infrastructure unclear. Thus, researchers preferred to use the concept of green infrastructure rather than EI.

In this study, urban ecological infrastructure (UEI) is defined as the organic integration of blue (water-based), green (vegetated), and grey (non-living) landscapes, combined with "exits" (outflows, treatment, or recycling) and "arteries" (corridors) at an ecosystem scale. The UEI plays a fundamental role in sustainably providing the ecosystem services that urban residents require. UEIs include a comprehensive set of functions: water supply and recycling, energy supply and heat dissipation, soil fertility and biodiversity, metabolism or breakdown of materials and regeneration of wastes, runoff reduction and nutrient retention, and the provision of recreational, educational and cultural services. The purpose of UEI development is to improve a city's ecological integrity and sustainability. A complete and healthy UEI is a basic requirement for secure and sustainable urban development and social interactions.

Traditional grey infrastructure uses a physical approach to transport the wastes and pollutions in cities to natural ecosystems, thus purifying the environment in urban areas. Green infrastructure pays attention to the biological approach (green and blue space etc.) to solve environmental problems and realize the importance 
of integration of different components, which is manifested by the pervasive practice of combining green spaces, greenways, natural reserves and wetlands. This integration is insufficient, however, as it only considers the connection of different components of green infrastructure and overlooks the wider inclusion of grey infrastructure. In addition, the integration is mainly at the structural level. The coupling of ecological processes and ecosystem function is only an assumption. Ecological infrastructure takes a holistic view and integrates ecological planning, engineering, design and technological approaches to solve urban environmental problems (e.g. pollution) and reduce the environmental impact of urban development on natural ecosystems. It combines grey and green infrastructure at an ecosystem scale and emphasizes the coordination of each component and the maximization of multiple system functions, instead of the function of single component (Li et al., 2014). A comparison of the reliability, cost-effectiveness, capacity of ecological infrastructure, green and grey infrastructures are shown in Fig. 3, which is further supported by the case study in Section 4.

\subsection{Structure}

UEI consists of blue land, green land, grey land, exits and arteries (Fig. 1) where:

- Blue land includes wetlands, lakes, ponds, streams and rivers with flowing and fluctuating water. It is an important constituent of urban ecological infrastructure and plays a crucial role in the urban environment, principally in water purification, flood control, groundwater replenishment and protection from storms.

- Green land includes urban parks, forests, farmland, green roofs and other natural or artificial green spaces. It provides indispensable ecosystem services, such as improving air quality, regulating the microclimate, maintaining biodiversity and beautifying the urban landscape.

- Grey land includes roads and highways, the electrical grid, artificial drainage systems and utilities. The presence of an activated or permeable surface allows the exchange of gas, water and nutrients between the soil and the atmosphere, thereby improving urban soil functions such as storage,

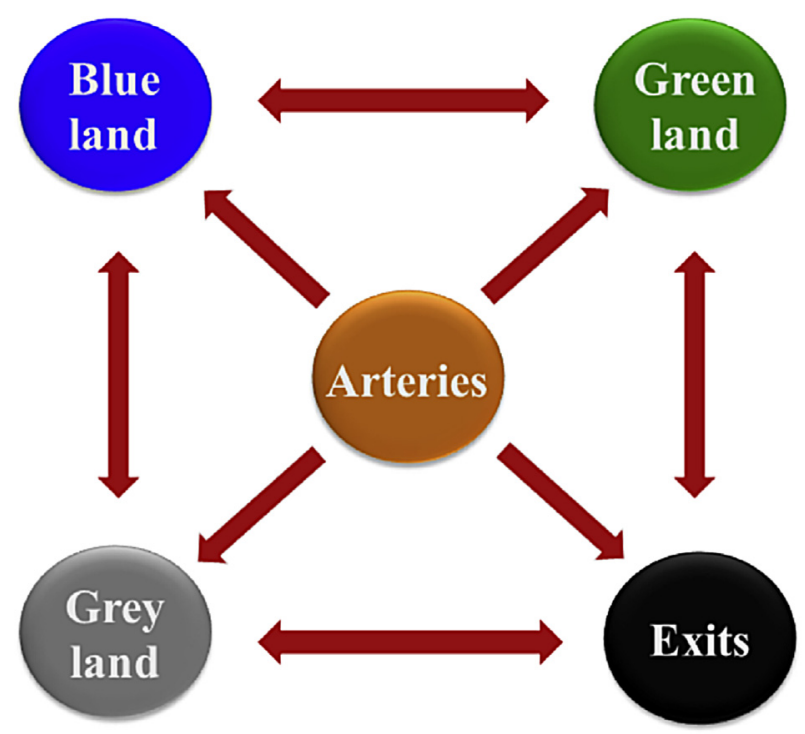

Fig. 1. Illustration of the integrated network for an urban ecological infrastructure. Grey land includes roads and highways, the electrical grid, drainage systems, and utilities. Green land includes urban forest, parks, woodland, green roofs, wetlands, rivers, and other natural spaces (see text for definitions).

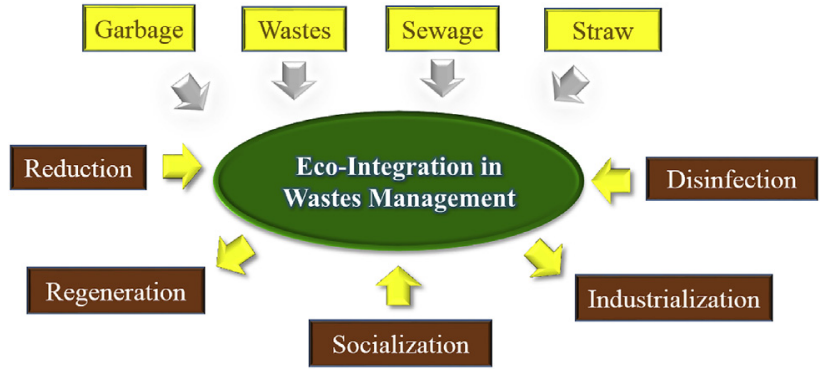

Fig. 2. Eco-integration in urban-rural waste management.

regulation, filtering, and biomass production, and remediating the adverse impacts caused by sealed urban soils. Restoring a permeable surface near important ecosystem services in urban areas would improve ecological functions.

- Exits represent flows of urban wastes, such sewage treatment facilities, air and emissions outlets and buffering belts. These differ from traditional waste discharge outlets, as they serve multiple functions: reduction and disposal, natural buffering and purification, artificial disinfection, "mining" of wastes, and resource regeneration and recycling.

- Arteries (corridors) include wind and water systems, channels, traffic lines, metabolism networks and any other ecological corridors that permit flows of materials between components of the UEI. Traffic networks (grey) and river systems (blue) are the basic arteries of the urban ecosystem. Practical, connected and unblocked arteries would alleviate traffic jams, mitigate air pollution and the heat island effect, and support ecosystem services

Although urban ecological infrastructure is different from grey infrastructure, green infrastructure and ecological networks, there are close relationships between them. Grey infrastructure is rigid, and mostly has a single function. It is expensive, energy-intensive, prone to deterioration or obsolescence, and does not scale. In contrast, green infrastructure is flexible and serves multiple functions. It is also less expensive and requires less on-going maintenance (Forest Research, 2010; Tzoulas et al., 2007). Blue infrastructure relates to flows of water through the system. Researchers have emphasized the creation and measurement of ecological (grey + green + blue) infrastructure systems that are inherently more systematic, adaptable and resilient than grey systems (Xu et al., 2012).

\subsection{Measurement}

Previous studies usually adopted ecological service function indicators and landscape pattern indicators to evaluate the function of EI. For the new concept of UEI proposed in this study, a more comprehensive set of indices should be developed for assessing UEI. This could include water use ratio (ratio of total water diverted away from natural use), fraction of land serving ecosystem services functions, renewable energy use ratio, proportion of native species, eco-efficiency of urban recycling and regeneration, and other similar indicators (Table 2).

\section{Building urban ecological infrastructure}

\subsection{Integration of each component}

\subsubsection{Blue land}

Wetlands and rivers are the main components of blue land in an urban ecosystem (Mitscha and Day, 2006). The links between rivers 


\begin{tabular}{llll}
\multicolumn{1}{c}{$\begin{array}{c}\text { Grey } \\
\text { infrastructure }\end{array}$} & \multicolumn{1}{c}{ UEI } \\
Costly & $\begin{array}{l}\text { Less cost } \\
\text { Rigid }\end{array}$ & Soft & Less cost \\
Single function & Multi-function & Rigid and soft combination \\
No integration & Integrating Soil, green & Multi-function \\
Regional Impacts & \& blue space & Ecosystem circulation \\
No resistance & Sectorial management & Integrative management \\
& Partial resistance & Self-organized and resilient
\end{tabular}

Fig. 3. Comparison of UEI, green and grey infrastructure. Note: UEI refers to urban ecological infrastructure.

Table 2

Comprehensive measurement indicators for urban ecological infrastructure.

\begin{tabular}{|c|c|c|}
\hline $\begin{array}{l}\text { Measurement } \\
\text { Indicators }\end{array}$ & Definitions & Critical Values \\
\hline $\begin{array}{l}\text { Ratio of water for urban use } \\
\text { versus natural use }\end{array}$ & $\begin{array}{l}\text { Ratio of water used for urban life and production } \\
\text { to that used for basic functions of the natural ecosystem. }\end{array}$ & Lower than $35 \%$ \\
\hline Land for ecosystem services & $\begin{array}{l}\text { Ratio of area of urban agriculture, forestry, grasslands, } \\
\text { wetlands, and nature reserves to area of urban construction. }\end{array}$ & $\begin{array}{l}\text { No less than twice the area } \\
\text { of construction land }\end{array}$ \\
\hline Renewable energy use ratio & $\begin{array}{l}\text { Ratio of geothermal, solar energy, wind energy, } \\
\text { biomass energy, hydropower, and other renewable } \\
\text { energy usage to the total energy usage. }\end{array}$ & No less than $10 \%$ \\
\hline Ratio of native species & Ratio of native species to all species. & No less than $65 \%$ \\
\hline Recycling rate & Recycling rate of renewable materials in urban metabolism. & No less than $90 \%$ \\
\hline
\end{tabular}

and lakes can increase the communication of organisms and materials in waters, and can enhance the abilities of water selfpurification, pollution digestion and ecological restoration. This helps protect urban wetlands, water resources, and aquatic biodiversity, and provides habitat for the ecological restoration of urban aquatic ecosystems (Li et al., 2011). On the other hand, blocked connections between rivers and lakes in urban areas will directly lead to the reduction of wetlands function and biodiversity, thus exacerbating the conflicts between urban environmental protection and socioeconomic development. In addition, through the organic combination and careful layout of wetlands of different types, the multiple functions and ecosystem services of wetlands such as water conservation and purification, climate regulation, water activation, and beautification of the landscape can be achieved. This would help to solve water eutrophication, flood disasters, decreasing biodiversity and other relevant urban environmental problems. Wetlands, ponds, rivers, etc., are natural "sponges" playing an important role in water seepage, retention, storage, purification and drainage, thus the reasonable layout of blue lands is a key step in sponge city construction. Through the integration of UEI (wetlands, green land, permeable pavements, etc.), the urban water ecological environment is repaired and the city is turned into a "sponge" with the capability for water retention, penetration and purification (Wu, 2016).

\subsubsection{Green land}

Currently, most of cities pay more attention to the form of green space rather than to its function, and in terms of quantity rather than quality, which results in urban green space that is fragmented and inefficient. In addition, uneven resource distribution and the invasion of urban green space by alien species not only aggravates the decline of urban ecological services, but also reduces the balance and sustainability of the urban ecosystem. Therefore, it is essential to integrate urban green spaces and form a network in order to improve ecosystem services, provide ecological corridors and habitat for urban organisms and guarantee urban ecological security (Camerona et al., 2012). This requires connected green spaces in and around urban and urban-fringe landscapes, including green parks, street-side green strips and, green roofs that are distributed in the inner city; and farmland, woodland, forest, etc., that are located in suburban areas; as well as green corridors and other ribbons of green space located throughout the city and its surroundings.

\subsubsection{Grey land}

Globally, the total impervious pavement area has reached $580,000 \mathrm{~km}^{2}$, larger than Spain's land area (Raciti et al., 2012). The massive extent of impervious surfaces in urban areas, including building surfaces, roads, ditches, banks, and other impervious pavement, blocks the exchange of air, water, and nutrients between soils and the atmosphere, thus significantly affecting urban ecosystem services and urban environments (Scalenghe and Marsan, 2009; Zhao et al., 2012). The integration of urban grey land into the UEI should reconstruct or restore the ecological functions of the urban "skin" (surface). Permeable pavement and vertical plantings are commonly used methods to mitigate the negative effects of impervious pavements, and have been demonstrated to be an effective tool for water conservation, storm-water runoff and water quality management, pollutant control, electricity savings, habitat provision for wildlife and soil function improvement.

\subsubsection{Exits}

The ecological infrastructure referred to as "exits" requires the integration and eco-renovation of pollutant discharge outlets, surrounding ecological buffer zones, and disposal facilities, as well as pollution reduction and purification systems, including pollution emissions, artificial disposal systems, natural buffer systems, and circulation feedback systems. This should be an ecological purification, disposal, circulation and regeneration system that combines artificial facilities and ecological facilities to achieve the goals of pollution reduction and neutralization, recycling, industrialization, and socialization. As shown in Fig. 2, the system shifts from a single pollutant discharge to ecosystem circulation, with an emphasis on 
waste reduction, reuse and recycling. In brief, using comprehensive social, economic and environmental management methods and carrying out adaptive ecological management should bring about effective solutions to urban pollution problems.

\subsubsection{Arteries}

Traffic, channels and wind and water systems are the framework of the urban ecosystem. The integration of urban "arteries" or corridors, based on function, can help to control urban sprawl and mitigate the problem of traffic congestion. The measures that could be taken may include the following: 1) distributing the urban ecological corridors throughout, with multiple functions for urban social and economic development; 2) highlight the city growth axis, shifting from urban sprawl to an ecologically sound development pattern (Li et al., 2005); 3) maintaining the functioning of the circulation network of city, people, material, air, and water-especially the urban wind channel and transportation network; 4) reconfigure and optimize the traffic hub, node, and transfer sites at different levels; and connect disconnected river segments and recover the groundwater drainage for surface water flows, thus allowing stagnant water to flow again; and 5) break up large areas of constructed landscape into smaller pieces through ecological engineering using green spaces, thus coupling urban ecological landscapes with constructed landscapes. In addition, urban corridors - namely the main traffic arteries - should carry more than 50 percent of the energy flow. Ecological traffic networks should serve more than 80 percent of the urban population. The time from any station of the main network to the city center by fast direct bus should be no more than half an hour, and from residential areas to work place normally not more than half an hour by bus.

\subsection{Integration of the system}

Unified planning, design, construction and management of blue land, green land, grey land, exits and arteries are essential for UEI integration, and can lead to the coordination, sustainability and stability of the whole system. Each component is not an isolated infrastructure, but functions in conjunction with other components to achieve multiple benefits and high efficiency. For instance, the complementary functions of wetlands, green space, and permeable pavement in organic combination with drainage pipelines and other arteries would efficiently reduce the risk of flood disasters.

Furthermore, we must look at the city as an integrated holistic urban ecosystem, where the UEI plays a crucial role. A spatial planning approach is one of the most effective ways to build up UEI. Previously, grey infrastructures and green infrastructure were considered to be two separate systems, each with its own advantages and disadvantages. Integrated spatial planning can bring different sectors together in order to combine their maximum force and effect, thus providing a more resilient, stable, and sustainable urban infrastructure system.

\section{Urban ecological infrastructure practices}

\subsection{A multiple wetlands system for flood control - a case study of Yangzhou City}

Yangzhou City is located at the intersection of the Yangtze River and the Great Canal, in Jiangsu Province, China. Frequent flooding has negatively affected the sustainable development of Yangzhou City. Wetlands restoration engineering in Shugang, Yangzhou, was adopted in 2008-2009, aiming to explore flood mitigation measures in an urban area and to provide a replicable demonstration project. In this project, we integrated blue land (three wetlands), green land (numerous green spaces) and grey land (permeable pavements) in a comprehensive ecologically engineered wetlands complex. After the completion of the project, the average annual maximum flood peak and average annual runoff were reduced by 91.27 percent and 98.81 percent, respectively. Moreover, the CODcr and $\mathrm{NH}_{3}-\mathrm{N}$ reduction ratios reached 42.8-64.6 percent and 25.2-64.9 percent, respectively. If Yangzhou City can further restore wetlands of equal effectiveness, the area inundated and the water pollution caused by flooding would be well controlled.

\subsection{Composite methods for pollution control - a case study in Hefei City}

In this case study, the control of water pollution was conducted at the river basin level. After calculating the sources and contributions of water pollution for Hefei City, China, we found that external pollution contributed 98-100 percent of the pollution; far more than internal pollution. External pollution can be further divided into point source pollution (28 percent) and non-point source pollution (71 percent) from industrial, domestic and urban-rural areas (He et al., 2013). Different approaches and measures, described below, were integrated to reduce the pollutants in order to improve the water quality in Chaohu Lake, Hefei City - one of the five largest freshwater lakes in China.

\subsubsection{Point source pollution: integrating exits and blue land}

Point source pollution was managed through a combination of grey infrastructure (urban sewage treatment systems) and the ecological engineering and management of rivers. In brief, industrial and domestic wastewater was first discharged into sewage treatment plants and then channeled into the eco-engineered land treatment (multi-stage ponds and wetlands) system established at the outlets of the sewage pipes. This successfully reduced water pollution and improved the water quality of Chaohu Lake.

\subsubsection{Non-point source pollution: multifunction wetlands systems}

Besides enhancing the UEI, the rural Bei-Tang system, used 3000 years ago in China, was also used to reduce non-point source pollution. The Bei-Tang system has multiple eco-services, including water storage, rainwater catchment, irrigation, transportation, flood control, drought prevention, nutrient recycling, microclimate regulation, pollutant treatment and degradation, and landscape aesthetics (Gao et al., 2015), and can be characterized as small scale, diversified, energy saving, and self-maintaining.

\subsubsection{Internal source pollution: multiple management approaches}

Lake and canal dredging, together with sediment management, were used to manage the internal source pollution. However, the key was in changing traditional ideas with eco-innovation: from environmental engineering to ecological engineering; from end-ofpipe to life-cycle management; from structure optimization to the evolution of functions; from external high-cost treatment to internal low-cost rehabilitation; and from physical restoration to comprehensive restoration based on social-economic-natural complex ecosystem.

\subsection{Integrated waste management systems at varied scales}

There are different scales of ecological infrastructure for integrated municipal solid waste management. At the household scale, scrapes of food waste can be put inside a small composter in a kitchen, and turned into compost within twenty-four hours; then the compost can then be applied to the yard and garden plants.

On the community scale, a waste recycling and organics composting center could provide an ecological infrastructure for 
municipal solid waste. Wastes would be separated by the household inhabitants and the recycling staff, then organic matter (normally more than 60 percent in China) would be aerobically treated in composting machines within twenty-four hours. The organics could be reduced to 70 percent wet weight, with a resulting nutrient content has been estimated at $\mathrm{N}=0.294-0.848 \mathrm{mg}$ per $\mathrm{kg} ; \mathrm{P}_{2} \mathrm{O}_{5}=0.499-1.105 \mathrm{mg}$ per $\mathrm{kg}$; $\mathrm{K}_{2} \mathrm{O}=0.274-0.899 \mathrm{mg}$ per $\mathrm{kg}$. This compost could then be applied as a sound organic fertilizer.

On the city scale, material recycling centers for papers, plastics, metals, etc., could be established to supply recycling services and reverse logistics for nearby communities. Regional composters could also be established for the communities that do not have enough space for decentralized waste management.

\section{Conclusions}

In summary, the UEI framework takes into account the biotic and abiotic interactions within an ecosystem emphasizes the connections among species (including humans) and the conservation of wildlife. It stresses a functional relationship between artificial systems and natural systems, links the grey, blue, and green infrastructures, and integrates these infrastructures via exits and arteries. It can improve the circulation and reuse of resources throughout the urban ecosystem. A comprehensive urban ecological infrastructure facilitates more rational urban development, and improves urban ecosystem services and regional sustainability.

Under the UEI framework, cities represent integrated holistic ecosystems. UEI construction provides the foundation for sustainable urban development and a suitable quality of life for urban residents. Therefore, the development of a forward-looking, integrated UEI is essential for sustainable urban systems. It is necessary to have unified planning, design, construction, and management of blue, green, and grey land, and their integration with exits and arteries, is necessary. No component can be isolated or have an independent infrastructure; rather, each must function in combination with the other components to provide multiple benefits and high resource-utilization efficiency. For instance, the organic combination and complementarity of wetlands, green space, permeable pavements, ecological corridors, drainage pipelines and arteries can reduce the risk of flood disasters while also improving the management of water resources.

In spite of the merits of ecological infrastructure, however, there are limitations. UEIs are based on understanding of the urban systems and how each component works in the complex urban system. Although understanding the form and function of UEIs is an important first step, innovative strategies must address challenging obstacles such as rigid thinking, institutional fragmentation and inflexible policies. New thinking and new ways of acting will be required to provide a more resilient, stable, and sustainable urban system.

\section{Acknowledgments}

This research was funded by the National Natural Science Foundation of China (71273254, 71533004). We thank Dr. Geoff Hart and Deborah Rogers for assistance with an earlier version of this manuscript.

\section{References}

Ahern, J., 1995. Greenways as a planning strategy. Landsc. Urban Plan. 33, 131-155. Cagno, E., Ambroggi, D.M., Grande, O., Trucco, P., 2011. Risk analysis of underground infrastructures in urban areas. Reliab. Eng. Syst. Saf. 96, 139-148.
Camerona, R.W.F., Blanus, T., Taylorc, J.E., Salisbury, A., Halstead, A.J., Henricot, B., Thompsond, K., 2012. The domestic garden-its contribution to urban green infrastructure. Urban For. Urban Green. 11, 129-137.

Daily, G., 1997. Nature's Services: Societal Dependence on Natural Ecosystems. Island Press.

Daily, G., Ellison, K., Myers, N., 2002. The New Economy of Nature. Island Press, Washington, D.C.

Forest Research, 2010. Benefits of Green Infrastructure. Forest Research, Farnham. Report by Forest Research.

Foster, J., Lowe, A, Winkelman, S., 2011. The value of green infrastructure for urban climate adaptation. Report by Cent. Clean Air Policy.

Gao, J., Wang, R.S., Huang, J.L., 2015. Ecological engineering for traditional Chinese agriculture-A case study of Beitang. Ecol. Eng. 76, 7-13.

Getter, K.L., Rowe, D.B., 2006. The role of green roofs in sustainable development. HortScience 41, 1276-1286.

Gill, S.E., Handley, J.F., Ennos, A.R., Pauleit, S., 2007. Adapting cities for climate change: the role of the green infrastructure. Built Environ. 33, 115-133.

He, Y., Wang, R.S., Wang, Y.J., 2013. Ecological restoration strategy of Chao Lake and spatial development guide of Hefei city. In: The 8th Urban Development and Planning Conference.

Hostetler, M., Allen, W., Meurk, C., 2011. Conserving urban biodiversity? Creating green infrastructure is only the first step. Landsc. Urban Plan. 100, 369-371.

Jim, C.Y., Chen, W.Y., 2008. Assessing the ecosystem service of air pollutant removal by urban trees in Guangzhou, China. J. Environ. Manag. 88, 665-676.

Kessler, R., 2011. Storm water strategies: cities prepare aging infrastructure for climate change. Environ. Health Prospect. 119, a514-a519.

Kjolle, G.H., Utne, I.B., Gjerde, O., 2012. Risk analysis of critical infrastructures emphasizing electricity supply and interdependencies. Reliab. Eng. Syst. Saf. $105,80-89$.

Li, F., Liu, X.S., Hu, D., Wang, R.S., Yang, W.R., Li, D., Zhao, D., 2009. Measurement indicators and an evaluation approach for assessing urban sustainable development: a case study for China's Jining city. Landsc. Urban Plan. 90, 134-142.

Li, F., Wang, R.S., Paulussen, J., Liu, X.S., 2005. Comprehensive concept planning of urban greening based on ecological principles: a case study in Beijing, China. Landsc. Urban Plan. 72, 325-336.

Li, F. Wang, R.S., Zhao, D., 2014. Urban ecological infrastructure based on ecosystem services: status, problems and perspectives. Acta Ecol. Sin. 34, 190-200 (in Chinese).

Li, F., Ye, Y.P., Song, B.W., Wang, R.S., 2015. Evaluation of urban suitable ecological land based on the minimum cumulative resistance model: a case study from Changzhou, China. Ecol. Model. 318, 194-203.

Li, Y.Y., Li, J.Q., Li, Z.L., Liu, X.J., Tian, Y., Li, A.H., 2011. Issues and challenges for the study of the interconnected river system network. Resour. Sci. 33, 386-391.

Lockhart, J., 2009. Green infrastructure: the strategic role of trees, woodlands and forestry. Arboric. J. 32, 33-49.

Mell, I.C., 2009. Can green infrastructure promote urban sustainability? Proc. Institution Civ. Eng. Eng. Sustain. 162, 23-24.

Mitscha, W.J., Day Jr., J.W., 2006. Restoration of wetlands in the Mississippi-Ohio-Missouri (MOM) River Basin: experience and needed research. Ecol. Eng. 26, 55-69.

Nolfi, S., Parisi, D., 1994. Good teaching inputs do not correspond to desired responses in ecological neural networks. Neural Process. Lett. 1, 1-4.

Patterson, S.A., Apostolakis, G.E., 2007. Identification of critical locations across multiple infrastructures for terrorist actions. Reliab. Eng. Syst. Saf. 92, 1183-1203.

Raciti, S.M., Hutyra, L.R., Finzi, A.C., 2012. Depleted soil carbon and nitrogen pools beneath impervious surfaces. Environ. Pollut. 164, 248-251.

Scalenghe, R., Marsan, F.A., 2009. The anthropogenic sealing of soils in urban areas. Landsc. Urban Plan. 90, 1-10.

Scholz, M., Grabowiecki, P., 2007. Review of permeable pavement systems. Build. Environ. 44, 3830-3836.

Schrijnen, P.M., 2000. Infrastructure networks and red-green patterns in city regions. Landsc. Urban Plan. 48, 191-204.

Serrano, M., Sanz, L., Puig, J., Pons, J., 2002. Landscape fragmentation caused by the transport network in Navarra (Spain): two-scale analysis and landscape integration assessment. Landsc. Urban Plan. 58, 113-123.

Sijtsma, F.J., Sjerp de, V.S.D., Hinsberg, A.V., Diederiks, J., 2012. Does 'grey’ urban living lead to more 'green' holiday nights? A Netherlands Case Study. Landsc. Urban Plan. 105, 250-257.

Sun, X., Li, F., Tao, Y., Song, Y.S., 2015. Comprehensive evaluation of different scale cities' sustainable development for economy, society, and ecological infrastructure in China. J. Clean. Prod. http://dx.doi.org/10.1016/j.jclepro.2015.09.002.

Tao, Y., Li, F., Wang, R.S., Zhao, D., 2015. Effects of land use and cover change on terrestrial carbon stocks in urbanized areas: a study from Changzhou, China. J. Clean. Prod. 103, 651-657.

The Conservation Fund, Arlington, VA. "Green Infrastructure." (accessed 06.10.09.)

Tzoulas, K., Korpela, K., Venn, S., Yli-Pelkonen, V., Kázmierczak, A., Niemela, J., James, P., 2007. Promoting ecosystem and human health in urban areas using Green Infrastructure: a literature review. Landsc. Urban Plan. 81, $167-178$.

United Nations, Department of Economic and Social Affairs, Population Division, 2012. World Urbanization Prospects: the 2011 Revision. CD-ROM Edition.

Wald, D.M., Hostetler, M.E., 2010. Conservation value of residential open space: designation and management language of Florida's land development regulations. Sustainability 2, 1536-1552. 
Wang, R.S., Li, F., Han, B.L., Huang, H.P., Yin, K., 2014. Urban eco-complex and ecospace management. Acta Ecol. Sin. 34, 1-11 (in Chinese).

Weber, T., Blank, P.J., Sloan, A., 2008. Field validation of a conservation network on the Eastern Shore of Maryland, USA, using breeding birds as bioindicators. Environ. Manag. 41, 538-550.

Wu, Y.G., 2016. Sponge City Design. Phoenix Science Press, Nanjing, p. 88.

Xu, M., Weissburg, M., Newell, J.P., Crittenden, J.C., 2012. Developing a science of infrastructure ecology for sustainable urban systems. Environ. Sci. Technol. 46, 7928-7929.

Yu, K.J., Li, D.H., Chao, L.M., 2001. Ten landscape strategies to build urban ecological infrastructure. Planners 6, 9-17.
Yu, K.J., Li, W., Li, D.H., Li, C.B., Huang, G., Liu, H.L., 2005. Suitability analysis of heritage corridor in rapidly urbanizing region: a case study of Taizhou City. Geogr. Res. 24, 69-76.

Yu, K.J., Xi, X.S., Wang, S.S., 2008. Townscape planning based on ecological infrastructure: a case study of Weihai, Shandong. City Plan. Rev. 32, 3.

Zhao, D., Li, F., Wang, R.S., Yang, Q.R., Ni, H.S., 2012. The effect of soil sealing on the microbial biomass, nitrogen transformation and related enzyme activities at various depths of soils in urban area of Beijing, China. J. Soils Sedim. 12, 519-530.

Zhang, X.L., 2016. Sustainable urbanization: a bi-dimensional matrix model. J. Clean Prod. 134 (Part A), 425-433. http://dx.doi.org/10.1016/j.jclepro.2015.08.036. 